Interobserver reliability of the chest radiograph in communityacquired pneumonia. Chest 1996;110(2):343-350.

10. Skrupky LP, McConnell K, Dallas J, Kollef MH. A comparison of ventilator-associated pneumonia rates as identified according to the National Healthcare Safety Network and American College of Chest Physicians criteria. Crit Care Med 2012;40(1):281284.

11. Thomas BW, Maxwell RA, Dart BW, et al. Errors in administrative-reported ventilator-associated pneumonia rates: are never events really so? Am Surg 2011;77(8):998-1002.

12. Novosel TJ, Hodge LA, Weireter LJ, et al. Ventilator-associated pneumonia: depends on your definition. Am Surg 2012;78(8): 851-854.

13. Klompas M, Magill S, Robicsek A, et al. Objective surveillance definitions for ventilator-associated pneumonia. Crit Care Med 2012;40(12):3154-3161.

14. Klompas M, Kleinman K, Khan Y, et al. Rapid and reproducible surveillance for ventilator-associated pneumonia. Clin Infect Dis 2012;54:370-377.

15. Magill SS, Klompas M, Balk R, et al. Developing a new, national approach to surveillance for ventilator-associated events. Crit Care Med 2013;41(11):2467-2475.

16. Klompas M, Khan Y, Kleinman K, et al. Multicenter evaluation of a novel surveillance paradigm for complications of mechanical ventilation. PLoS ONE 2011;6(3):e18062.

17. Hayashi Y, Morisawa K, Klompas M, et al. Toward improved surveillance: the impact of ventilator-associated complications on length of stay and antibiotic use in patients in intensive care units. Clin Infect Dis 2013;56(4):471-477.

18. Klein Klouwenberg PM, van Mourik MS, Ong DS, et al. Electronic implementation of a novel surveillance paradigm for ventilator-associated events: feasibility and validation. Am J Respir Crit Care Med. 2014;189(8):947-955.

19. Mekontso Dessap A, Katsahian S, Roche-Campo F, et al. Ventilator-associated pneumonia during weaning from mechanical ventilation: role of fluid management. Chest 2014;146(1):58-65.

20. Klompas M. Complications of mechanical ventilation-the CDC's new surveillance paradigm. N Engl J Med 2013;368(16): 1472-1475.

21. Klompas M. Ventilator-associated events surveillance: a patient safety opportunity. Curr Opin Crit Care 2013;19(5):424-431.

22. Muscedere J, Sinuff T, Heyland D, et al. The clinical impact and preventability of ventilator-associated conditions in critically ill mechanically ventilated patients. Chest 2013;144(5):1453-1460.

23. Klompas M, Li L. Beyond pneumonia: improving care for ventilated patients. Lancet Infect Dis 2013;13(8):640-641.

\section{Impact of Physicians' Mindfulness Attitudes toward Prevention of Catheter-Associated Urinary Tract Infection}

To the Editor-In an earlier report, an evidence-based mindfulness practice model for bedside infection prevention practices was explored in the context of catheter-associated uri- nary tract infections (CA-UTIs). ${ }^{1}$ We now explore the impact of physician mindfulness attitudes toward practices to prevent CA-UTI at Thammasat University Hospital (Pathumthani, Thailand). In this hospital, a physician order is required before catheterization, and a system to remind physicians to remove catheters is in place. ${ }^{2}$

From March 1 to March 31, 2014, we interviewed all physicians who removed Foley catheters within 24 hours after a reminder to remove a urinary catheter (group 1), physicians who did not remove Foley catheters within 24 hours after a reminder to do so (group 2), and physicians who did not order insertion of a Foley catheter (group 3). Patients were categorized into groups on the basis of retrospective review of an infection control database. All 3 groups were matched by the hospital department (eg, Department of Medicine and Department of Surgery) in a $1: 1: 1$ ratio. Data collection included physician demographic characteristics, hospital unit, level of training (eg, intern, resident, and staff), and mindfulness attitudes. Mindfulness attitudes were defined as awareness of perceptions related to urinary catheter placement, awareness of benefits and risks of urinary catheter placement, awareness of appropriate indication of catheterization, consideration of essential patient factors (eg, disease process, incontinence, and morbidity) before inserting catheter, synthesis of patient-specific context (eg, infection risk and availability of staff) before inserting catheter, and consideration of behavioral or therapeutic alternative options (eg, hourly voiding prompt) before inserting catheter, as defined by an earlier study. ${ }^{1}$ Appropriate Foley catheter insertion was defined as obstruction to the urinary tract distal to the bladder, close monitoring of urine output in critically ill patients, fluid challenge in patients with acute renal insufficiency, preoperative insertion, urinary retention, and urinary incontinence that poses a risk to the patient (eg, because of major skin breakdown or a nearby surgical site). The $\chi^{2}$ or Fisher exact test was used to compare categorical data, as appropriate. Continuous variables were compared using Student $t$ test. All $P$ values were 2-tailed; $P$ less than .05 was considered to be statistically significant.

There were 75 patients deemed eligible for inclusion (group 1, 26 patients; group 2, 24 patients; group 3,25 patients). Physician demographic characteristics, level of training, and attitudes toward mindfulness in urinary catheterization revealed several prescriber differences (Table 1). Compared with group 1, group 3 physicians reported a greater awareness of perception related to urinary catheter placement (20 [80\%] of 25 vs 8 [31\%] of $26 ; P<.001$ ), greater awareness of benefits and risks of catheter placement (21 [84\%] of 25 vs 8 [31\%] of 26; $P<.001$ ), and greater awareness of appropriate catheter insertion indications (23 [92\%] of 25 vs 6 [23\%] of 26 ; $P<.001)$. Compared with group 2 , group 3 physicians reported greater awareness for all measured mindfulness attitudes to prevent CA-UTI (Table 1). Compared with group 2 , group 1 physicians were more likely to be aware of benefits 
TA B LE 1. Characteristics of 75 Physicians for Knowledge, Attitudes, and Skill Related to Urinary Catheter Care among Hospitalized Patients

\begin{tabular}{llcc}
\hline Characteristic & $\begin{array}{c}\text { Group 1 } \\
(n=26)\end{array}$ & $\begin{array}{c}\text { Group 2 } \\
(n=24)\end{array}$ & $\begin{array}{c}\text { Group 3 } \\
(n=25)\end{array}$ \\
\hline Age & $28(24-41)$ & $\begin{array}{l}27(22-44) \\
\text { Male sex }\end{array}$ & $25(24-45)$ \\
Level of training & $16(62)$ & $14(58)$ & $15(60)$ \\
$\quad$ Intern & $8(31)$ & $7(29)$ & $8(32)$ \\
Resident, year 1-3 & $16(62)$ & $15(63)$ & $15(60)$ \\
Staff & $2(8)$ & $2(8)$ & $2(8)$ \\
Hospital unit & & & \\
Medicine & $6(23)$ & $6(25)$ & $6(24)$ \\
Surgery & $6(23)$ & $5(21)$ & $5(20)$ \\
Intensive care & $5(19)$ & $4(17)$ & $5(20)$ \\
Orthopedics & $5(19)$ & $5(21)$ & $5(20)$ \\
Obstetrics and gynecology & $2(8)$ & $2(8)$ & $2(8)$ \\
Ophthalmology and otolaryngology & $2(8)$ & $2(8)$ & $2(8)$ \\
Awareness of mindfulness attitudes & & & \\
Perceptions related to urinary catheter placement & $8(31)^{\mathrm{a}}$ & $4(17)^{\mathrm{a}}$ & $20(80)$ \\
Benefits and risks of urinary catheter placement & $8(31)^{\mathrm{a}}$ & $1(4)^{\mathrm{a}, \mathrm{b}}$ & $21(84)$ \\
Appropriate indication of catheterization & $6(23)^{\mathrm{a}}$ & $3(12)^{\mathrm{a}}$ & $23(92)$ \\
Consideration of essential patient factors & $7(27)$ & $4(17)^{\mathrm{a}}$ & $13(52)$ \\
Synthesis of patient-specific context & $7(27)$ & $4(17)^{\mathrm{a}}$ & $13(52)$ \\
Considerations of alternative options & $7(27)$ & $4(17)^{\mathrm{a}}$ & $13(52)$ \\
\hline
\end{tabular}

NOTE. Data are no. (\%) of physicians, unless indicated otherwise. Group 1, physicians who removed urinary catheter within 24 hours after reminder to remove catheter; group 2, physicians who did not remove catheter within 24 hours after reminder to remove catheter; group 3, physicians who did not order catheter placement.

a $P<.05$, compared with group 3 .

b $P<.05$, compared with group 1 .

and risks of urinary catheter placement (8 [31\%] of 26 vs 1 [4\%] of $24 ; P=.02$ ).

Although limited by small sample size, our findings suggest that physicians who did not order urinary catheter placement were more mindful, compared with physicians who ordered urinary catheters. A mindful practitioner would also recognize and capitalize on possible benefits of a mindful action. Because awareness and consideration of the patient and contextual situation and knowledge of added benefits related to an intervention are critical to making the best possible decision for the patient, future physician education on CA-UTI prevention would have to incorporate these mindfulness components into the prevention strategies. Future studies to translate the mindfulness model into infection prevention practices are needed.

\section{ACKNOWLEDGMENTS}

We thank Dr Linda Mundy for her critical review of the manuscript. Financial support. A.A. and T.K. were supported by the National Research University Project of the Thailand Office of Higher Education Commission. Potential conflicts of interest. All authors report no conflicts of interest relevant to this article. All authors submitted the ICMJE Form for Disclosure of Potential Conflicts of Interest, and the conflicts that the editors consider relevant to this article are disclosed here.

Anucha Apisarnthanarak, MD; ${ }^{1}$

Pansachee Damronglerd, MD; ${ }^{1}$ Atibordee Meesing, MD; ${ }^{1}$ Sasinuj Rutjanawech, MD; ${ }^{1}$ Thana Khawcharoenporn, MD $^{1}$

Affiliation: 1. Division of Infectious Diseases, Faculty of Medicine, Thammasat University, Pathumthani, Thailand.

Address correspondence to Anucha Apisarnthanarak, MD, Division of Infectious Diseases, Thammasat University Hospital, Pratumthani, Thailand 12120 (anapisarn@yahoo.com).

Infect Control Hosp Epidemiol 2014;35(9):1198-1200

(C) 2014 by The Society for Healthcare Epidemiology of America. All rights reserved. 0899-823X/2014/3509-0020\$15.00. DOI: $10.1086 / 677642$

\section{REFERENCES}

1. Kiyoshi-Teo H, Krein SL, Saint S. Applying mindful evidencebased practice at the bedside: using catheter-associated urinary tract infection as a model. Infect Control Hosp Epidemiol 2013; 34:1099-1101.

2. Apisarnthanarak A, Thongphubeth K, Sirinvaravong S, et al. Effectiveness of multifaceted hospitalwide quality improvement 
programs featuring an intervention to remove unnecessary urinary catheters at a tertiary care center in Thailand. Infect Control Hosp Epidemiol 2007;28:791-798.

\section{A Formula for Infection Control Using Colonization Pressure and Compliance Rates}

To the Editor-Colonized and infected patients are a major reservoir for the patient-to-patient transmission of nosocomial pathogens within hospitals. The prevalence of colonized patients, termed "colonization pressure," is an important risk factor for the development of nosocomial infections. Colonization pressure is formally defined as the number of colonized patient-days $\times 100 /$ total patient-days. ${ }^{1}$ Bonten et $\mathrm{al}^{2}$ first described the role of colonization pressure in the spread of vancomycin-resistant enterococci (VRE) and showed that, when VRE colonization pressure increased threefold, from $25 \%$ to $75 \%$, the days until VRE acquisition decreased by one-third, from 16-18 days to 6-7 days. This indicates that, as colonization pressure increases threefold, the transmission velocity or power increases threefold. This group also reported that, when colonization pressure reached $50 \%$, it became an independent variable that determined VRE acquisition but was not affected by infection control measures, including handwashing and the wearing of personal protective equipment (PPE; eg, gloves, gowns and aprons, and masks). In methicillin-resistant Staphylococcus aureus (MRSA) nosocomial infections, the same relationship between the colonization pressure and the infection risk was observed. ${ }^{3}$ These findings suggested that low colonization pressure might reduce the likelihood of MRSA transmission even in settings with low rates of compliance to infection control measures, whereas high colonization pressure could result in transmission even in settings with high rates of compliance to infection control measures. Thus, a high colonization pressure may have the ability to negate infection control efficacy. ${ }^{4}$

This negation is thought to arise because the rate of compliance to infection control measures is generally assumed to be $30 \%-80 \%$, and reaching a $100 \%$ rate of compliance is difficult. ${ }^{5}$ Even at an $80 \%$ compliance rate, $20 \%$ of interactions are still noncompliant with infection control measures. If many carriers exist (ie, under high colonization pressure), the chance of direct contact (with carriers) and indirect contact (with the environment around carriers) increases, and the absolute number of noncompliant interactions also increases. However, low colonization pressure does not result in a high absolute number of potential contacts with infectious pathogens, even if the compliance rate is low. Overall, infection strength seems to be correlated with colonization pressure and inversely proportional to the rate of compliance to infection control measures.

Using the 2 variables of colonization pressure and compliance rate, transmission risk (ie, transmission velocity or transmission power) could simply be expressed as follows: transmission risk $=$ colonization pressure $(\%)$ of nosocomial pathogens/compliance rate (\%) of infection control measure. For instance, according to the formula, in the case of a low colonization pressure (eg, 10\%) and an ordinary compliance rate (eg, $40 \%$ ), the transmission risk can be calculated as $10 /$ $40=0.25$. However, in the case of a high colonization pressure (eg, 40\%) and a high compliance rate (eg, 80\%), the transmission risk can be calculated as $40 / 80=0.5$. Thus, even if the compliance rate is increased twofold and colonization is increased fourfold, the transmission risk is increased twofold. The compliance rate is limited by human nature, and therefore, if the prevalence of carriers becomes high, the chance of contact inevitably increases. The results of this formula suggest that, when many carriers exist in a ward, infection control practices may not be effective.

In terms of colonization, we need to consider the degree of environmental contamination surrounding carriers. As the degree of bacterial shedding from colonized patients increases, contamination of the environment increases; that is, the colonization pressure increases. Wang et $\mathrm{al}^{6}$ proposed that the colonization pressure is adjusted by the degree of environmental contamination. The modified colonization pressure, calculated by multiplying colonization pressure by the degree of environmental contamination, can be used for the formula. In addition, contamination is not limited to environmental surfaces. Infectious agents are transmitted via aerial droplet cloud, ${ }^{7,8}$ which could spatially or three-dimensionally enhance the colonization pressure and further spread infectious agents.

Colonization pressure could be defined as the total amount of infectious agents in an environment contaminated by carriers. The more rigorously that healthcare workers perform infection control measures, including hand hygiene and barrier precautions, the less easily infectious agents can be transmitted to patients. This phenomenon is similar to conditions in which resistance interrupts electric current. Infection control measures create resistance against infectious flow. If the total amount of infectious agents (ie, voltage) is high and infection control (ie, resistance) is low, the transmission (ie, current) becomes intense. Thus, the proposed formula could mimic Ohm's law regarding electric circuits, as follows: infectious current $=$ total amount of infectious agents in an environment/resistance to transmission to patients. In light of the formula, the measure of infection control can be divided into the 2 basic categories: colonization pressure (the numerator) and compliance rate (the denominator).

Controlling colonization pressure involves the following: early hospital discharge of colonized patients, isolation precautions, decolonization therapy, decreasing the quantity of 